\title{
2008/15
}

Interdependent preferences in the design of equal-opportunity policies

Juan D. Moreno-Ternero 
CORE

Voie du Roman Pays 34

B-1348 Louvain-la-Neuve, Belgium.

Tel (32 10) 474304

Fax (32 10) 474301

E-mail: corestat-library@uclouvain.be http://www.uclouvain.be/en-44508.html 


\title{
CORE DISCUSSION PAPER
}

$2008 / 15$

\section{Interdependent preferences in the design of equal-opportunity policies}

\author{
Juan D. MORENO-TERNERO ${ }^{1}$
}

March 2008

\begin{abstract}
We study mechanisms to construct equal-opportunity policies for resource allocation. In our model agents enjoy welfare as a function of the effort they expend, and the amount of a socially provided resource they consume. Nevertheless, agents have interdependent preferences, i.e., they not only care about their own allocation, but also about their peers' allocations. As in the standard approach to equality of opportunity, the aim is to allocate the social resource so that welfare across individuals at the same relative effort level is as equal as possible. We show how pursuing this same aim while assuming that agents have interdependent preferences might crucially alter the results.
\end{abstract}

Keywords: equality of opportunity, interdependent preferences, social policies, compensation, responsibility.

JEL Classification: D63, H00, I18

\footnotetext{
${ }^{1}$ Universidad de Malaga, Spain and CORE, Université catholique de Louvain, Belgium.

I owe my gratitude to John Roemer for his inspiring work and stimulating conversations which are the main reason why I became interested in the formal study of equality of opportunity. I retain, however, the responsibility for any shortcomings in the outcomes of my study. I am also most grateful to Dirk van de Gaer for helpful comments and suggestions. Thanks are also due to the audience at the ECINEQ's Second Biannual Conference (Berlin, 2007). Financial support from the Spanish Ministry of Education and Science (SEJ 2005-04805) and Junta de Andalucia (P06-SEJ-01645) is gratefully acknowledged.

This paper presents research results of the Belgian Program on Interuniversity Poles of Attraction initiated by the Belgian State, Prime Minister's Office, Science Policy Programming. The scientific responsibility is assumed by the author.
} 



\section{Introduction}

Distributive justice concerns the fair distribution of social welfare among the citizens of a society. Probably, the most universally supported conception of distributive justice is that of equality of opportunity. Traditionally, equality of opportunity was understood as the absence of legal bar to access to education, to all positions and jobs, and the fact that all hiring was meritocratic. From the 70's, several authors, most notably, John Rawls (e.g., Rawls, 1971), Amartya Sen (e.g., Sen, 1980) and Ronald Dworkin (e.g., Dworkin, 1981a; 1981b), started calling for a more radical notion of equality of opportunity. Nowadays, it is well accepted that real equality of opportunity requires compensating individuals for aspects of their situation for which they are not responsible (and that hamper their achievement of whatever is valuable in life) but only for those (differences between aspects of their situations for which they are responsible should not be a concern for justice).

John Roemer (e.g., Roemer, 1993, 1998) has formalized a precise (and quite influential) notion of equality of opportunity in order to resolve distributive issues. ${ }^{1}$ In a pure distribution context, a policy reduces to a proposal for the allocation of some finite amount of resource, across types of individuals, where the resource is to be interpreted as the instrument to achieve a certain objective. Roemer postulates that an equal-opportunity policy, with respect to an objective, should allocate the resource so that it makes the degree to which an individual achieves the objective a function only of her effort (i.e., aspects that influence the individual's status but over which she has at least some control), and therefore independent of her circumstances (i.e., aspects beyond the individual's control that also influence her status).

Roemer's mechanism is constructed under the standard assumption in most economic models that all people are exclusively motivated by their material self-interest (the so-called self-interest hypothesis). That is, in his model, Roemer assumes that agents have "independent preferences", hence only caring about their own allocations. In recent years, however, there has been experimental and field evidence systematically refuting the self-interest hypothesis and suggesting that many people are strongly motivated by others' preferences and that concerns for fairness and reciprocity cannot be ignored in social interactions (e.g., Guth et al., 1982; Fehr et al., 1993; Fehr

\footnotetext{
${ }^{1}$ It is worth noting that Roemer's theory has a broader range of applications although we shall restrict our attention here to the pure distribution context, for ease of exposition.
} 
and Gachter, 2000). As a result, several models that relax the assumption of individual greed, upon expanding the notion of preferences, to account for the above evidence, have been proposed (e.g., Fehr and Schmidt, 1999; Bolton and Ockenfels, 2000). A feature that most of these models share is that individuals dislike payoff inequality and that individual preferences also depend on the payoff of others.

If a social planner cares about equality of opportunity, it seems reasonable to assume that (at least, some) agents do too. ${ }^{2}$ An agent caring about equality of opportunity is likely to care about social goals per se and not just about material self-interest. Therefore, in order to design equal-opportunity policies, it makes sense to assume that agents have interdependent preferences instead of self-interest (independent) preferences. This is indeed the aim of this paper. That is, to explore the design of equal-opportunity policies in the event in which individuals not only care about their own allocation, but also about their peers' allocations, where here peer is interpreted as an equally deserving (in terms of relative effort) individual. We shall formalize a suitable mechanism for the design of equal-opportunity policies in this context and will highlight how the assumption of interdependent preferences can make a difference with respect to the standard approach to equality of opportunity. Our mechanism will be mostly framed as an extension to Roemer's original mechanism. As we shall see later, it can also be easily adapted to account for the suitable extension of a different, but somewhat related, mechanism developed by Dirk Van de gaer (e.g., Van de gaer, 1993; Ooghe et al., 2007). ${ }^{3}$

The related literature to this paper can be divided into two broad categories.

On the one hand, the literature on compensation and responsibility in fair allocation rules (see Fleurbaey and Maniquet (2004) or Fleurbaey (2008) for excellent surveys). This literature deals with two antagonistic principles (to neutralize the influence over agents' outcomes of the characteristics that elicit compensation, and to do nothing about inequalities entailed by other characteristics) typically modeled by axioms which are logically independent, and even sometimes substantially incompatible. The main issue then is to solve the ethical dilemma of how to balance these two principles in the social allocation of resources. The mechanism presented in this paper can

\footnotetext{
${ }^{2}$ Except, perhaps, if the social planner endorses the enlightened despotism' maxim "everything for the people, nothing by the people".

${ }^{3}$ Van de gaer's mechanism focuses on the opportunity sets (i.e., sets of available outcomes) of equally-deserving individuals in different types, rather than focusing on their actual outcomes (as Roemer's mechanism does).
} 
be considered as a step in that direction. ${ }^{4}$

On the other hand, the literature on interdependent preferences (see Fehr and Schmidt (2003) or Sobel (2005) for excellent surveys). As mentioned above, research on interdependent preferences mostly originated to give account of the growing empirical and experimental evidence that human behavior could not be explained only by the hypothesis of self-interested material payoff maximization. In this paper, we make use of one of the (successful) existing models accounting for this evidence so that the design of equal-opportunity policies becomes more accurate.

The rest of the paper is organized as follows. In Section 2, we introduce the preliminaries of the model. In Section 3, we present the standard and new mechanisms to construct equal-opportunity policies. In Section 4, we provide an application to obtain equal-opportunity policies in the context of health care delivery. Section 5 concludes.

\section{The model}

Consider a population whose members enjoy welfare as a result of the amount of a socially provided resource they consume, and the amount of effort they expend. The amount of effort an individual expends comes determined, not only by her autonomous volition, but also by her circumstances. We assume there is a fixed set of circumstances and let $T=\{1, \ldots, n\}$ be the set of resulting types, in which the population is exhaustively partitioned (i.e., two individuals in the same type share the same profile of circumstances, whereas individuals in different types have different profiles). Each type is characterized by a function denoted $u^{t}(\cdot, \cdot)$ representing the material welfare of an individual of type $t$, as a function of the amount of the resource she consumes and the effort she expends. We assume that these utility functions are fully interpersonally comparable. That is, $u^{t}(x, e) \geq u^{t^{\prime}}\left(x^{\prime}, e^{\prime}\right)$ means that an individual in type $t$, who receives an amount of resource $x$ and expends a level of effort $e$, enjoys at least the same material welfare

\footnotetext{
${ }^{4}$ To be more precise, the mechanism in this paper refers to the so-called utilitarianreward approach to equality of opportunity (also adopted by Roemer and Van de gaer) which postulates that the social objective is to maximize the sum of individual outcomes, once the undue influence of characteristics calling for compensation has properly been taken into account. There is an opposite approach based on the libertarian principle that if all agents were identical in the characteristics which elicit compensation, there would be no reason to make any transfer between the agents (the so-called natural-reward principle). See Fleurbaey and Maniquet (2004) or Fleurbaey (2008) for further scrutiny of both reward principles, as well as their connections with the principle of compensation.
} 
level than an individual in type $t^{\prime}$, who receives an amount of resource $x^{\prime}$ and expends a level of effort $e^{\prime} .^{5}$

Suppose that there exists an amount $\omega$ (per capita) of the resource to allocate among individuals in the population. The issue is to determine how to allocate $\omega$ properly to achieve equality of opportunity. For each $t \in T$, let $\varphi^{t}: \mathcal{R}_{+} \longmapsto \mathcal{R}_{+}$be the function that indicates the amount of resource that an individual of type $t$ receives with respect to the effort she expends. An $n$-tuple $\varphi=\left(\varphi^{1}, \ldots, \varphi^{n}\right)$ of such functions will be called a policy and each of its components $\varphi^{t}$ will be called an allocation rule. Let $\Phi$ be the set of available policies.

Suppose that the distribution of effort expended by members of type $t$ is given by the probability measure $F_{\varphi^{t}}^{t}$. Let $e^{t}\left(\pi, \varphi^{t}\right)$ be the level of effort expended by the individual at the $\pi^{t h}$ quantile of that effort distribution. Formally, $e^{t}\left(\pi, \varphi^{t}\right)$ is such that

$$
\pi=\int_{0}^{e^{t}\left(\pi, \varphi^{t}\right)} d F_{\varphi^{t}}^{t}
$$

Now, we define the indirect material utility function $v^{t}\left(\pi, \varphi^{t}\right)$, i.e., the level of material welfare enjoyed by an individual of type $t$ who reached the $\pi^{t h}$ degree of effort and faced the allocation rule $\varphi^{t}$, as follows:

$$
v^{t}\left(\pi, \varphi^{t}\right)=u^{t}\left(\varphi^{t}\left(e^{t}\left(\pi, \varphi^{t}\right)\right), e^{t}\left(\pi, \varphi^{t}\right)\right) .
$$

Let $\pi \in[0,1]$ and $\varphi=\left(\varphi^{1}, \ldots, \varphi^{n}\right) \in \Phi$ be given and consider

$$
v(\pi, \varphi)=\left(v^{1}\left(\pi, \varphi^{1}\right), v^{2}\left(\pi, \varphi^{2}\right), \ldots, v^{n}\left(\pi, \varphi^{n}\right)\right)
$$

the vector of indirect material utilities of the individuals at the $\pi^{t h}$ degree of effort of each type, after implementing policy $\varphi$.

Now, we also assume that individuals enjoy immaterial welfare that comes determined by their peers' material welfare levels, where here 'peers' refers to agents that are equally deserving, i.e., agents expending a comparable level of effort. ${ }^{6}$ In other words, individuals are not necessarily purely selfish subjects and they might dislike inequitable outcomes for individuals who are equally deserving. As modeled by Fehr and Schmidt (1999),

\footnotetext{
${ }^{5}$ For instance, think of the case of future earning power as a function of the (per capita) expenditure in education and years of schooling. Also, think of life expectancy, or the number of QALYs, as a function of the (per capita) health care expenditure and the life style (e.g., smoking behavior, physical exercise, etc.)

${ }^{6}$ Here, and following Roemer (1998), comparable effort will refer to the same relative effort level, i.e., the same quantile at the corresponding effort distribution.
} 
we assume that, in general, individuals suffer more from inequity that is to their material disadvantage than from inequity that is to their material advantage. Formally, let $V^{t}(\cdot, \cdot)$ denote the function representing the overall (material and immaterial) welfare of an individual of type $t$, as a function of her quantile at the type's effort distribution and the policy being implemented. Then, for $\pi \in[0,1]$ and $\varphi=\left(\varphi^{1}, \ldots, \varphi^{n}\right) \in \Phi$, we have

$$
\begin{aligned}
V^{t}(\pi, \varphi) & =v^{t}\left(\pi, \varphi^{t}\right) \\
& -\frac{\alpha^{t}}{n-1} \sum_{s \in T \backslash\{t\}} \max \left\{v^{s}\left(\pi, \varphi^{s}\right)-v^{t}\left(\pi, \varphi^{t}\right), 0\right\} \\
& -\frac{\beta^{t}}{n-1} \sum_{s \in T \backslash\{t\}} \max \left\{v^{t}\left(\pi, \varphi^{t}\right)-v^{s}\left(\pi, \varphi^{s}\right), 0\right\},
\end{aligned}
$$

where $\alpha^{t} \geq \max \left\{0, \beta^{t}\right\}$. Note that the first term measures the utility loss from disadvantageous inequality, while the second term measures the loss from advantageous inequality. Furthermore, the assumption $\alpha^{t} \geq \beta^{t}$ captures the idea that an individual suffers more from inequality that is to her disadvantage. Note also that we do not impose the standard assumption of $\beta^{t} \geq 0$, as we do not want to rule out from the outset the existence of subjects who like to be better off than their peers.

\section{The mechanisms}

The issue now is to construct a mechanism that yields for each environment a particular policy in $\Phi$. For a given quantile $\pi$ of effort expended, suppose we are only concerned with equalizing the advantage of all individual, across types, who expended the $\pi^{t h}$ degree of effort. For this case, Roemer (1998, page 27) proposes to select the policy that maximizes the minimum level of material advantage of these individuals. Formally,

$$
\varphi_{\pi}=\arg \max _{\varphi \in \Phi} \min _{t \in T}\left\{v^{t}\left(\pi, \varphi^{t}\right)\right\} .
$$

If, instead, the goal would be adjusted to consider immaterial advantage too, the program would become

$$
\widehat{\varphi}_{\pi}=\arg \max _{\varphi \in \Phi} \min _{t \in T}\left\{V^{t}(\pi, \varphi)\right\} .
$$

At the risk of stressing the obvious, note that whereas program (1) is only concerned with the material advantage achieved by the worst-off individual, out of those at the same (relative) level of effort, program (2) 
is concerned with the whole distribution of material advantage within the group. It is also worth noting, nonetheless, that if we assume $\alpha^{t}=\beta^{t}=0$, for all $t \in T$, in program (2), then we obtain program (1), which shows that program (2) is indeed a generalization of program (1), to account for possible interdependent preferences.

Now, if we wish to equalize advantage across types for every $\pi$, either using program (1) or program (2), we would have in general a continuum of different policies, $\left\{\varphi_{\pi}: \pi \in[0,1]\right\}$ or $\left\{\widehat{\varphi}_{\pi}: \pi \in[0,1]\right\}$. If, by chance, all the programs would provide the same policy, that would be, unambiguously, the equal-opportunity policy recommended. In general, this will not be the case and therefore we need to adopt a compromise solution. To do so, Roemer (1998) proposes a modification of program (1) upon replacing the maximandum for a social objective function consisting of the average of the maximanda in each of the programs. More precisely,

$$
\varphi^{R}=\arg \max _{\varphi \in \Phi} \int_{0}^{1} \min _{t \in T}\left\{v^{t}(\pi, \varphi)\right\} d \pi .
$$

The analogous extension of our proposal would generate the following program:

$$
\widehat{\varphi}=\arg \max _{\varphi \in \Phi} \int_{0}^{1} \min _{t \in T}\left\{V^{t}(\pi, \varphi)\right\} d \pi .
$$

As mentioned above, there is a similar approach to equality of opportunity that focuses on the opportunity sets to which people have access (rather than their outcomes), and tries to make these sets as equal as possible (e.g., Van de gaer, 1993; Ooghe et al., 2007). Formally, for $\varphi \in \Phi$, let $v_{\varphi}$ be the average of the indirect (material) utilities of each type at each degree of effort, after implementing $\varphi$, i.e.,

$$
v_{\varphi}=\left(\int_{0}^{1} v^{1}\left(\pi, \varphi^{1}\right) \cdot d \pi, \ldots, \int_{0}^{1} v^{n}\left(\pi, \varphi^{n}\right) \cdot d \pi\right) .
$$

Each component of the representative vector $v_{\varphi}$ can be interpreted as the opportunity set of each type. Then, Van de gaer's mechanism amounts to the following program:

$$
\varphi^{V}=\arg \max _{\varphi \in \Phi} \min _{t \in T}\left\{\int_{0}^{1} v^{t}\left(\pi, \varphi^{t}\right) \cdot d \pi\right\} .
$$

The counterpart mechanism for interdependent preferences would then be the following:

$$
\widehat{\varphi}^{V}=\arg \max _{\varphi \in \Phi} \min _{t \in T}\left\{\int_{0}^{1} V^{t}(\pi, \varphi) \cdot d \pi\right\} \text {. }
$$




\subsection{A particular case}

For ease of exposition, and in order to gain some insight on the effect of interdependent preferences in the design of equal-opportunity policies, let us focus now on the two-type case. Formally, let $T=\{1,2\}$. For $\pi \in[0,1]$ and $\varphi=\left(\varphi^{1}, \varphi^{2}\right) \in \Phi$, we have

$$
\begin{aligned}
V^{1}(\pi, \varphi) & =v^{1}\left(\pi, \varphi^{1}\right) \\
& -\alpha^{1} \max \left\{v^{2}\left(\pi, \varphi^{2}\right)-v^{1}\left(\pi, \varphi^{1}\right), 0\right\} \\
& -\beta^{1} \max \left\{v^{1}\left(\pi, \varphi^{1}\right)-v^{2}\left(\pi, \varphi^{2}\right), 0\right\},
\end{aligned}
$$

where $\alpha^{1} \geq \max \left\{0, \beta^{1}\right\}$, and,

$$
\begin{aligned}
V^{2}(\pi, \varphi) & =v^{2}\left(\pi, \varphi^{2}\right) \\
& -\alpha^{2} \max \left\{v^{1}\left(\pi, \varphi^{1}\right)-v^{2}\left(\pi, \varphi^{2}\right), 0\right\} \\
& -\beta^{2} \max \left\{v^{2}\left(\pi, \varphi^{2}\right)-v^{1}\left(\pi, \varphi^{1}\right), 0\right\}
\end{aligned}
$$

where $\alpha^{2} \geq \max \left\{0, \beta^{2}\right\}$.

Let us now assume that type 1 is handicapped with respect to type 2 , i.e., for any $\varphi=\left(\varphi^{1}, \varphi^{2}\right) \in \Phi$ given, $v^{1}\left(\pi, \varphi^{1}\right) \leq v^{2}\left(\pi, \varphi^{2}\right)$ for all $\pi \in[0,1]$. Thus, the above expressions become

$$
V^{1}(\pi, \varphi)=v^{1}\left(\pi, \varphi^{1}\right)-\alpha^{1}\left(v^{2}\left(\pi, \varphi^{2}\right)-v^{1}\left(\pi, \varphi^{1}\right)\right),
$$

and

$$
V^{2}(\pi, \varphi)=v^{2}\left(\pi, \varphi^{2}\right)-\beta^{2}\left(v^{2}\left(\pi, \varphi^{2}\right)-v^{1}\left(\pi, \varphi^{1}\right)\right) .
$$

Then, it is straightforward to show that, for $\varphi=\left(\varphi^{1}, \varphi^{2}\right) \in \Phi$ and $\pi \in[0,1]$ given, $V^{1}(\pi, \varphi) \leq V^{2}(\pi, \varphi)$ if and only if $\alpha^{1} \geq \beta^{2}-1$. Therefore, program (4) would become

$$
\max _{\varphi \in \Phi}\left(1+\alpha^{1}\right) \int_{0}^{1} v^{1}(\pi, \varphi) d \pi-\alpha^{1} \int_{0}^{1} v^{2}(\pi, \varphi) d \pi
$$

for the case in which $\alpha^{1} \geq \beta^{2}-1$, and

$$
\max _{\varphi \in \Phi} \beta^{2} \int_{0}^{1} v^{1}(\pi, \varphi) d \pi+\left(1-\beta^{2}\right) \int_{0}^{1} v^{2}(\pi, \varphi) d \pi,
$$

for the case in which $\alpha^{1} \leq \beta^{2}-1$. Program (7), however, would become

$$
\max _{\varphi \in \Phi} \int_{0}^{1} v^{1}(\pi, \varphi) d \pi
$$


which clearly highlights the differences in policy recommendations between the case of interdependent preferences and the case of independent preferences.

For instance, it is not difficult to show that if the average (material) advantage of the handicapped group (i.e., $\int_{0}^{1} v^{1}(\pi, \varphi) d \pi$ ) is a single-peaked function with respect to $\varphi$, whereas the average (material) advantage of the other group (i.e., $\int_{0}^{1} v^{2}(\pi, \varphi) d \pi$ ) is an increasing function with respect to $\varphi$ (as it will be the case for the illustration in the next section), then we have that the resulting equal-opportunity policy upon assuming interdependent preferences (i.e., the solution to program (7), or to program (8)) gives more priority to the handicapped group than the resulting equal-opportunity policy upon assuming independent preferences (i.e., the solution to program (9)).$^{7}$

\section{An illustration: equal-opportunity policies for health care}

We show in this section, by means of a stylized example, that when it comes to design equal-opportunity policies, considering interdependent preferences can make a difference. This example comes from Roemer (2002) and it is presented here with some slight modifications. ${ }^{8}$ It consists of a framework to select equal-opportunity policies for the delivery of health care resources.

Assume a society with two types of individuals, the rich and the poor, where we suppose that a person is not to be held accountable for her socioeconomic status in regard to her health. Let us say that one half of the population is poor whilst the other half is rich. The rich have, on average, more healthy life styles than the poor. This is formalized by assuming that the poor have life-style qualities uniformly distributed on the interval $[0,1]$, while the rich have life-style qualities that are uniformly distributed on the interval $[0.5,1.5]$.

We suppose that members of the population die from cancer or tuberculosis. The probability of contracting cancer, as a function of life-style quality $(q)$, is the same for both types, and given by:

$$
\rho_{R}^{C}(q)=\rho_{P}^{C}(q)=1-\frac{2 q}{3}
$$

whereas the probability of contracting tuberculosis is only positive for the

\footnotetext{
${ }^{7}$ For a study of the ethics of priority see Moreno-Ternero and Roemer (2006).

${ }^{8}$ See also Moreno-Ternero (2007).
} 
poor people and given by:

$$
\rho_{P}^{T}(q)=1-\frac{q}{3}
$$

In particular, the rich do not contract tuberculosis at all. Suppose that life expectancy for a rich individual has the following expression:

$L E_{R}=\left\{\begin{array}{l}70 \text { if cancer is not contracted, } \\ 60+10 \frac{x_{c}-1000}{x_{c}+1000} \text { if cancer is contracted and } x_{c} \text { is spent on its treatment. }\end{array}\right.$

Thus, if the disease is contracted, life expectancy will lie between 50 and 70 , depending on how much is spent on treatment (from zero to an infinite amount). This is a simple way of modeling the fact that nobody dies of cancer before age 50, that life expectancy increases as resources spent increase and approaches 70 if resources spent become infinite. Suppose that life expectancy for a poor individual is

$$
L E_{P}=\left\{\begin{array}{l}
70 \text { if neither disease is contracted, } \\
60+10 \frac{x_{c}-1000}{x_{c}+1000} \text { if cancer is contracted and } x_{c} \text { is spent on its treatment. } \\
50+20 \frac{x_{t}-10000}{x_{t}+10000} \text { if tuberculosis is contracted and } x_{t} \text { is spent on it. } \\
\min \left\{60+10 \frac{x_{c}-1000}{x_{c}+1000}, 50+20 \frac{x_{t}-10000}{x_{t}+10000}\right\} \text { if both diseases are contracted. }
\end{array}\right.
$$

Thus, the poor can die at age 30 if they contract tuberculosis and it is not treated. With large expenditures, an individual who contracts tuberculosis can live to age 70 . We also assume that if a poor individual contracts both cancer and tuberculosis then her life expectancy will be the minimum of the above two numbers.

Finally, assume that national health care budget is $\$ 4000$ per capita.

The instrument is $\left(x_{c}, x_{t}\right)$, the schedule of how much will be spent on treating an occurrence of each disease. The objective is to equalize opportunities, for the rich and the poor, for life expectancy.

With the data mentioned above, one can easily compute that $1 / 3$ of the rich will contract cancer, $1 / 9$ of the poor will contract only cancer, $5 / 18$ of the poor will contract only tuberculosis and $5 / 9$ of the poor will contract both tuberculosis and cancer. Hence, the budget constraint can be expressed as

$$
\left(\frac{1}{2} \cdot \frac{1}{3}+\frac{1}{2} \cdot \frac{2}{3}\right) x_{c}+\frac{1}{2} \cdot \frac{5}{6} \cdot x_{t}=4000
$$

or equivalently, $6 x_{c}+5 x_{t}=48000$.

It is also straightforward to see that the probability that individuals at quantile $\pi$ of their effort distribution contract a disease is: 


\begin{tabular}{|l|l|l|}
\hline & CANCER & TUBERCULOSIS \\
\hline RICH & $1-\frac{2}{3}(\pi+0.5)$ & 0 \\
\hline POOR & $1-\frac{2}{3} \pi$ & $1-\frac{\pi}{3}$ \\
\hline
\end{tabular}

Thus, life expectancies are

$$
v_{R}\left(\pi, x_{c}\right)=\frac{2}{3}(\pi+0.5) \cdot 70+\left(\frac{2}{3}(1-\pi)\right)\left(60+10 \frac{x_{c}-1000}{x_{c}+1000}\right)
$$

and

$$
\begin{aligned}
v_{P}\left(\pi, x_{c}, x_{t}\right)= & \frac{2 \pi^{2}}{9} \cdot 70+\left(1-\frac{\pi}{3}\right) \frac{2 \pi}{3}\left(50+20 \frac{x_{t}-10000}{x_{t}+10000}\right)+ \\
& \left(1-\frac{2 \pi}{3}\right) \frac{\pi}{3}\left(60+10 \frac{x_{c}-1000}{x_{c}+1000}\right)+ \\
& \left(1-\frac{\pi}{3}\right)\left(1-\frac{2 \pi}{3}\right) \min \left\{60+10 \frac{x_{c}-1000}{x_{c}+1000}, 50+20 \frac{x_{t}-10000}{x_{t}+10000}\right\}
\end{aligned}
$$

The solution that Roemer's mechanism would propose for this example is obtained by solving the problem:

$$
\begin{gathered}
\max _{\left\{x_{c}, x_{t}\right\}}\left\{\int_{0}^{1} \min \left\{v_{R}\left(\pi, x_{c}\right), v_{P}\left(\pi, x_{c}, x_{t}\right)\right\} \cdot d \pi\right\} \\
\text { s.t. } 6 x_{c}+5 x_{t}=48000
\end{gathered}
$$

It can be shown that, for $\left(x_{c}, x_{t}\right)$ given, $v_{R}\left(\pi, x_{c}\right) \geq v_{P}\left(\pi, x_{c}, x_{t}\right)$ for all $\pi \in[0,1]$. Thus, the above program becomes

$$
\begin{array}{r}
\max _{\left\{x_{c}, x_{t}\right\}}\left\{\int_{0}^{1} v_{P}\left(\pi, x_{c}, x_{t}\right) \cdot d \pi\right\} \\
\text { s.t. } 6 x_{c}+5 x_{t}=48000
\end{array}
$$

whose solution turns out to be

$$
\left(x_{c}^{R}, x_{t}^{R}\right)=(\$ 310, \$ 9230),
$$

i.e., $\$ 310$ spent in the treatment of cancer and $\$ 9230$ in the treatment of tuberculosis. ${ }^{9}$

\footnotetext{
${ }^{9}$ Note that this would also be the solution that Van de gaer's mechanism would propose here, as it would amount to solve the same problem given that, in this example, opportunity sets do not cross (e.g., Ooghe et al., 2007).
} 
Let us now assume that individuals have interdependent preferences. That is, they not only care about their life expectancies, but also about their peers' life expectancy, where here 'peers' refers to agents at the same quantile of their corresponding life-style distributions. Formally, let

$$
\begin{aligned}
V_{P}\left(\pi, x_{c}, x_{t}\right) & =v_{P}\left(\pi, x_{c}, x_{t}\right) \\
& -\alpha_{P} \max \left\{v_{R}\left(\pi, x_{c}\right)-v_{P}\left(\pi, x_{c}, x_{t}\right), 0\right\} \\
& -\beta_{P} \max \left\{v_{P}\left(\pi, x_{c}, x_{t}\right)-v_{R}\left(\pi, x_{c}\right), 0\right\}
\end{aligned}
$$

where $\alpha_{P} \geq \max \left\{\beta_{P}, 0\right\}$, and

$$
\begin{aligned}
V_{R}\left(\pi, x_{c}, x_{t}\right) & =v_{R}\left(\pi, x_{c}\right) \\
& -\alpha_{R} \max \left\{v_{P}\left(\pi, x_{c}, x_{t}\right)-v_{R}\left(\pi, x_{c}\right), 0\right\} \\
& -\beta_{R} \max \left\{v_{R}\left(\pi, x_{c}\right)-v_{P}\left(\pi, x_{c}, x_{t}\right), 0\right\},
\end{aligned}
$$

where $\alpha_{R} \geq \max \left\{\beta_{R}, 0\right\}$.

Since, for $\left(x_{c}, x_{t}\right)$ given, $v_{R}\left(\pi, x_{c}\right) \geq v_{P}\left(\pi, x_{c}, x_{t}\right)$ for all $\pi \in[0,1]$, we have the following:

$$
V_{P}\left(\pi, x_{c}, x_{t}\right)=v_{P}\left(\pi, x_{c}, x_{t}\right)-\alpha_{P}\left(v_{R}\left(\pi, x_{c}\right)-v_{P}\left(\pi, x_{c}, x_{t}\right)\right)
$$

and

$$
V_{R}\left(\pi, x_{c}, x_{t}\right)=v_{R}\left(\pi, x_{c}\right)-\beta_{R}\left(v_{R}\left(\pi, x_{c}\right)-v_{P}\left(\pi, x_{c}, x_{t}\right)\right)
$$

For these preferences, program (4) translates into

$$
\begin{aligned}
& \max _{\left\{x_{c}, x_{t}\right\}}\left\{\int_{0}^{1} \min \left\{V_{P}\left(\pi, x_{c}, x_{t}\right), V_{R}\left(\pi, x_{c}\right)\right\} \cdot d \pi\right\} \\
& \text { s.t. } 6 x_{c}+5 x_{t}=48000
\end{aligned}
$$

Let us assume first that $\alpha_{P} \geq \beta_{R}-1$. Then, it follows that, for $\left(x_{c}, x_{t}\right)$ given, $V_{R}\left(\pi, x_{c}, x_{t}\right) \geq V_{P}\left(\pi, x_{c}, x_{t}\right)$ for all $\pi \in[0,1]$. Thus, program (4) translates into

$$
\begin{array}{r}
\max _{\left\{x_{c}, x_{t}\right\}}\left\{\int_{0}^{1} V_{P}\left(\pi, x_{c}, x_{t}\right) \cdot d \pi\right\} \\
\text { s.t. } 6 x_{c}+5 x_{t}=48000
\end{array}
$$

Equivalently,

$$
\begin{aligned}
& \max _{\left\{x_{c}, x_{t}\right\}}\left\{\left(1+\alpha_{P}\right) \int_{0}^{1} v_{P}\left(\pi, x_{c}, x_{t}\right)-\alpha_{P} \int_{0}^{1} v_{R}\left(\pi, x_{c}\right) \cdot d \pi\right\} \\
& \text { s.t. } 6 x_{c}+5 x_{t}=48000
\end{aligned}
$$

Obviously, for $\alpha_{P}=0$ this program becomes Roemer's original program. For $\alpha_{P}>0$, however, we have different programs and different solutions. 
More precisely, let $\widehat{\alpha}=0.13842$. Then, it turns out that for $\alpha_{P} \geq \widehat{\alpha}$ the solution is given by

$$
\left(x_{c}, x_{t}\right)=(\$ 0, \$ 9600)
$$

i.e., everything is spent in the treatment of tuberculosis. For $0<\alpha_{P}<\widehat{\alpha}$, the corresponding programs have $\alpha_{P}$-specific solutions $\left(x_{c}, x_{t}\right)=\left(x_{c}^{\alpha_{P}}, x_{t}^{\alpha_{P}}\right)$, moving from Roemer's solution to the above solution. Figure 1 plots all of them as a function of $\alpha_{P}$.

\section{Insert Figure 1 about here}

If we now assume that $\alpha_{P} \leq \beta_{R}-1$, results do not change. More precisely, under this assumption, $V_{R}\left(\pi, x_{c}, x_{t}\right) \leq V_{P}\left(\pi, x_{c}, x_{t}\right)$ for all $\pi \in[0,1]$. Thus, program (4) translates into

$$
\begin{gathered}
\max _{\left\{x_{c}, x_{t}\right\}}\left\{\beta_{R} \int_{0}^{1} v_{P}\left(\pi, x_{c}, x_{t}\right)+\left(1-\beta_{R}\right) \int_{0}^{1} v_{R}\left(\pi, x_{c}\right) \cdot d \pi\right\} \\
\text { s.t. } 6 x_{c}+5 x_{t}=48000
\end{gathered}
$$

Then, for $\beta_{R}=1$, which is the lowest possible value for $\beta_{R}$ (and equivalent to the case in which $\alpha_{P}=0$ ) under the assumption $\alpha_{P} \leq \beta_{R}-1$, this program becomes Roemer's original program. For $\beta_{R} \geq 1+\widehat{\alpha}=1.13842$, the solution is given by

$$
\left(x_{c}, x_{t}\right)=(\$ 0, \$ 9600)
$$

i.e., everything is spent in the treatment of tuberculosis. For $1<\beta_{R}<$ 1.13842 , the corresponding programs have $\beta_{R}$-specific solutions that coincide with the $\alpha_{P}$-specific solutions described above. ${ }^{10}$ Thus, no new solutions emerge under the assumption $\alpha_{P} \leq \beta_{R}-1$.

In summary, we obtain that, for this example, all possible solutions under the assumption of interdependent preferences involve a higher expenditure on the disease which is specific to the poor type than under the assumption of selfish preferences. Formally, $x_{c}<x_{c}^{R}$ and $x_{t}>x_{t}^{R}{ }^{11}$

To conclude, it is worth mentioning that the policy in which everything is spent in the treatment of tuberculosis is precisely the so-called Rawlsian policy (i.e., the policy that maximizes the condition of the worst-off individual) for this example. Formally, the Rawlsian policy is given by the program

$$
\varphi^{R W}=\arg \max _{\varphi \in \Phi} \min _{(t, \pi) \in T \times[0,1]}\left\{v^{t}(\pi, \varphi)\right\} .
$$

\footnotetext{
${ }^{10}$ More precisely, for $1<\beta_{R}<1.13842,\left(x_{c}^{\beta_{R}}, x_{t}^{\beta_{R}}\right)=\left(x_{c}^{1+\alpha_{P}}, x_{t}^{1+\alpha_{P}}\right)$.

${ }^{11}$ This feature is also obtained under more general conditions, as mentioned in Section 3.1 .
} 
It is not difficult to show that the solution of this program, for the example of this section, is obtained by solving the problem:

$$
\begin{gathered}
\max _{\left\{x_{c}, x_{t}\right\}}\left\{v_{P}\left(0, x_{c}, x_{t}\right)\right\} \\
\text { s.t. } 6 x_{c}+5 x_{t}=48000
\end{gathered}
$$

whose solution turns out to be $\left(x_{c}^{R W}, x_{t}^{R W}\right)=(\$ 0, \$ 9600)$. Therefore, a small degree of inequity aversion in individuals' preferences is enough to guarantee a broad consensus on the Rawlsian solution, at least for this problem.

\section{Discussion}

Equality of opportunity amounts to combine the idea of compensation with the concept of responsibility for the design of policies. Roemer's theory of equality of opportunity is a very important contribution in this direction, providing perhaps the first workable proposal (in an economic model) to design equal-opportunity policies, by means of a precise balance between the ideas of compensation and responsibility. ${ }^{12}$ The theory assumes the socalled self-interest hypothesis, by which all individuals are assumed to be exclusively pursuing their material self-interest without caring about "social" goals per se. In this paper, we have argued that interdependent preferences (which have proven to be useful in explaining several puzzles arising under the self-interest hypothesis) might be more consonant with the idea of equality of opportunity. We have also shown that the counterpart mechanism to Roemer's original mechanism, extended to incorporate interdependent preferences, might yield recommendations that are significantly different.

It is worth remarking that the introduction of interdependent preferences in the model we have considered does not preclude the existence of agents obeying the standard economic assumptions of rationality and individual greed. One of the insights of some of the newly developed theoretical models with interdependent preferences is to argue that the interaction between fair and selfish individuals is key to understand the observed behavior in strategic settings (e.g., Fehr and Schmidt, 1999; Bolton and Ockenfels, 2000). These models explain why in some strategic settings almost all people behave as if they are completely selfish, while in others the same people will behave as if they are driven by fairness. In this respect, our mechanism is a generalization of Roemer's (and also Van de gaer's) mechanism, which

\footnotetext{
${ }^{12}$ Other important contributions balancing the ideas of compensation and responsibility in a general framework, as well as in applications, have recently appeared in the literature (e.g., Fleurbaey and Maniquet, 2004; 2006; Ooghe et al., 2007; Fleurbaey, 2008).
} 
can be seen as an extreme case in which all agents in the model are selfish. Our mechanism, however, allows for more realistic situations in which individuals do care about social goals, such as fairness in the allocation process, relative deprivation, and status seeking.

A somewhat related modification to Roemer's (and also Van de gaer's) approach to the design of equal-opportunity policies has also been recently proposed (e.g., Moreno-Ternero, 2007). In this case, the idea is to recommend the policy that minimize the inequality (according to a certain inequality index) of welfare across individuals that are equally deserving. In doing so, a concern for relative deprivation and status seeking is captured, albeit without imposing interdependent preferences in the model. Interestingly enough, the case in which the maximin inequality index is considered gives rise to a mechanism that can be derived from Roemer's (and also Van de gaer's) mechanism upon assuming interdependent preferences, provided there is a sufficiently high concern for inequality aversion (see Moreno-Ternero (2007) for further details).

We have also provided in this paper an application of these mechanisms to the case of designing equal-opportunity policies for the finance of health care in a stylized example. We have shown in this example that a small concern for equity, among equally deserving agents, is enough to recommend more radical solutions than the ones advocated by Roemer's (and Van de gaer's) mechanism, even leading to the Rawlsian recommendation for this setting. Rawlsian policies have often been criticized for being too extreme as a result of not invoking any concern for individual responsibility. Our results, however, show that Rawlsian recommendations can actually be supported by a responsibility-sensitive theory of egalitarianism, such as the one proposed in this paper.

This work leaves two main routes for further research. On the one hand, it would be desirable to provide general (analytical) results extending the features highlighted in the application presented in this paper. For instance, to characterize the domains in which the equal-opportunity policies obtained under the assumption of interdependent preferences are more egalitarian than in the case of selfish preferences, or the domains in which the equalopportunity policies with interdependent preferences lead to the Rawlsian recommendation. On the other hand, it would be interesting to explore an alternative interpretation of the model in which agents are assumed to care about their peers' allocation, where peer now is interpreted as individuals at the same type (i.e., with the same set of circumstances) rather than at the same level (or degree) of effort, which might be an interpretation more in tune with Van de gaer's approach to the design of equal-opportunity policies. 


\section{References}

[1] Bolton, G., Ockenfels, A., (2000), ERC: A Theory of Equity, Reciprocity and Competition, American Economic Review 90, 166-193.

[2] Dworkin, R. (1981a), What is equality? Part 1: Equality of welfare. Philosophy \& Public Affairs 10, 185-246.

[3] Dworkin, R. (1981b), What is equality? Part 2: Equality of resources. Philosophy \& Public Affairs 10, 283-345.

[4] Fehr, E., Gachter, S., (2000), Cooperation and Punishment in Public Goods Experiments, American Economic Review 90, 980-994

[5] Fehr, E., Kirchsteiger, G., Riedl, A., (1993), Does Fairness prevent Market Clearing? An Experimental Investigation, Quarterly Journal of Economics 108, 437-460

[6] Fehr, E., Schmidt, K., (1999), A Theory of Fairness, Competition and Cooperation, Quarterly Journal of Economics 114, 817-868

[7] Fehr, E., Schmidt, K., (2003), Theories of Fairness and ReciprocityEvidence and Economic Applications, in Advances in Economics and Econometrics: 8th World Congress. M. Dewatripont, L. P. Hansen, and S. J. Turnovsky, eds. Cambridge University Press. Cambridge.

[8] Fleurbaey, M., (2008), Fairness, Responsibility, and Welfare, Oxford University Press.

[9] Fleurbaey M. and Maniquet, F. (2004), Compensation and Responsibility. Forthcoming in The Handbook for Social Choice and Welfare, Arrow, K., Sen, A., Suzumura, K. (eds.)

[10] Fleurbaey M., and Maniquet, F. (2006), Fair income tax, Review of Economic Studies 73, 55-83.

[11] Guth, W., Schmittberger, R., Schwarze, B., (1982), An Experimental Analysis of Ultimatum Bargaining, Journal of Economic Behavior and Organization 3, 367-88.

[12] Moreno-Ternero, J.D., (2007), On the design of equal opportunity policies, Investigaciones Econmicas 31, 351-374. 
[13] Moreno-Ternero, J.D., and Roemer, J. (2006), Impartiality, priority and solidarity in the theory of justice. Econometrica 74, 1419-1427.

[14] Ooghe, E., Schokkaert, E., Van de gaer, D., (2007), Equality of Opportunity versus Equality of Opportunity Sets, Social Choice and Welfare 28, 209-230.

[15] Rawls, J. (1971), A Theory of Justice. Harvard University Press. Cambridge, Ma.

[16] Roemer, J.E. (1993), A pragmatic theory of responsibility for the egalitarian planner. Philosophy \& Public Affairs 22, 146-166.

[17] Roemer, J.E. (1998), Equality of Opportunity. Harvard University Press. Cambridge, Ma.

[18] Roemer, J.E. (2002), Equity in health care delivery. Mimeo. Yale University.

[19] Sen, A. (1980), Equality of what? In Tanner Lectures on Human Values, Vol. I. Cambridge University Press.

[20] Sobel, J., (2005), Interdependent Preferences and Reciprocity, Journal of Economic Literature 43, 392-436

[21] Van de gaer, D. (1993), Equality of Opportunity and Investment in Human Capital, Ph. D thesis, K.U. Leuven. 


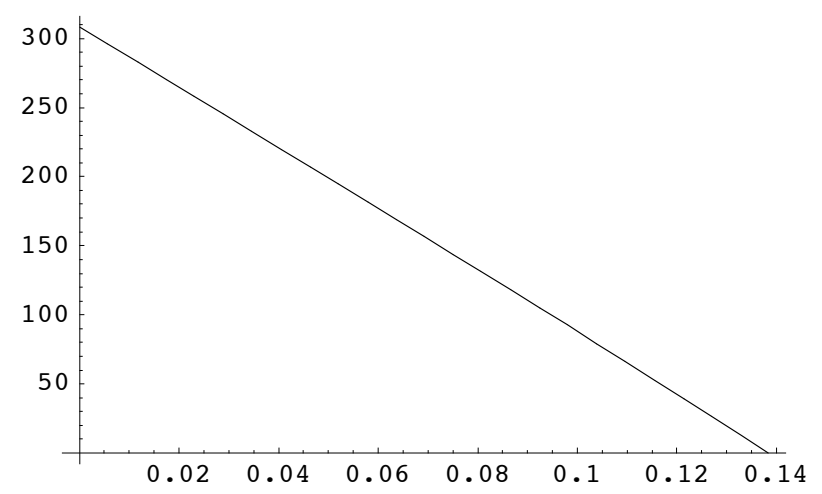

This figure plots the amount spent on cancer as a function of the parameter $\alpha$, for $0 \leq \alpha \leq 0.13842$.

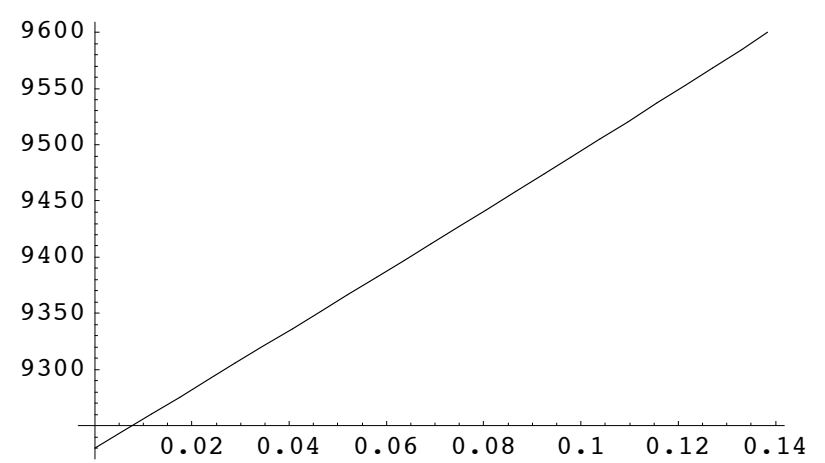

This figure plots the amount spent on tuberculosis as a function of the parameter $\alpha$, for $0 \leq \alpha \leq 0.13842$. 


\section{Recent titles \\ CORE Discussion Papers}

2007/71. Robert CHARES and François GLINEUR. An interior-point method for the single-facility location problem with mixed norms using a conic formulation.

2007/72. David DE LA CROIX and Omar LICANDRO. 'The child is father of the man': Implications for the demographic transition.

2007/73. Jean J. GABSZEWICZ and Joana RESENDE. Thematic clubs and the supremacy of network externalities.

2007/74. Jean J. GABSZEWICZ and Skerdilajda ZANAJ. A note on successive oligopolies and vertical mergers.

2007/75. Jacques H. DREZE and P. Jean-Jacques HERINGS. Kinky perceived demand curves and Keynes-Negishi equilibria.

2007/76. Yu. NESTEROV. Gradient methods for minimizing composite objective function.

2007/77. Giacomo VALLETTA. A fair solution to the compensation problem.

2007/78. Claude D'ASPREMONT, Rodolphe DOS SANTOS FERREIRA and Jacques THEPOT. Hawks and doves in segmented markets: a formal approach to competitive aggressiveness.

2007/79. Claude D'ASPREMONT, Rodolphe DOS SANTOS FERREIRA and Louis-André GERARDVARET. Imperfect competition and the trade cycle: guidelines from the late thirties.

2007/80. Andrea SILVESTRINI. Testing fiscal sustainability in Poland: a Bayesian analysis of cointegration.

2007/81. Jean-François MAYSTADT. Does inequality make us rebel? A renewed theoretical model applied to South Mexico.

2007/82. Jacques H. DREZE, Oussama LACHIRI and Enrico MINELLI. Shareholder-efficient production plans in a multi-period economy.

2007/83. Jan JOHANNES, Sébastien VAN BELLEGEM and Anne VANHEMS. A unified approach to solve ill-posed inverse problems in econometrics.

2007/84. Pablo AMOROS and M. Socorro PUY. Dialogue or issue divergence in the political campaign?

2007/85. Jean-Pierre FLORENS, Jan JOHANNES and Sébastien VAN BELLEGEM. Identification and estimation by penalization in nonparametric instrumental regression.

2007/86. Louis EECKHOUDT, Johanna ETNER and Fred SCHROYEN. A benchmark value for relative prudence.

2007/87. Ayse AKBALIK and Yves POCHET. Valid inequalities for the single-item capacitated lot sizing problem with step-wise costs.

2007/88. David CRAINICH and Louis EECKHOUDT. On the intensity of downside risk aversion.

2007/89. Alberto MARTIN and Wouter VERGOTE. On the role of retaliation in trade agreements.

2007/90. Marc FLEURBAEY and Erik SCHOKKAERT. Unfair inequalities in health and health care.

2007/91. Frédéric BABONNEAU and Jean-Philippe VIAL. A partitioning algorithm for the network loading problem.

2007/92. Luc BAUWENS, Giordano MION and Jacques-François THISSE. The resistible decline of European science.

2007/93. Gaetano BLOISE and Filippo L. CALCIANO. A characterization of inefficiency in stochastic overlapping generations economies.

2007/94. Pierre DEHEZ. Shapley compensation scheme.

2007/95. Helmuth CREMER, Pierre PESTIEAU and Maria RACIONERO. Unequal wages for equal utilities.

2007/96. Helmuth CREMER, Jean-Marie LOZACHMEUR and Pierre PESTIEAU. Collective annuities and redistribution.

2007/97. Mohammed BOUADDI and Jeroen V.K. ROMBOUTS. Mixed exponential power asymmetric conditional heteroskedasticity.

2008/1. Giorgia OGGIONI and Yves SMEERS. Evaluating the impact of average cost based contracts on the industrial sector in the European emission trading scheme.

2008/2. Oscar AMERIGHI and Giuseppe DE FEO. Privatization and policy competition for FDI. 


\section{Recent titles}

\section{CORE Discussion Papers - continued}

2008/3. Wlodzimierz SZWARC. On cycling in the simplex method of the Transportation Problem.

2008/4. John-John D'ARGENSIO and Frédéric LAURIN. The real estate risk premium: A developed/emerging country panel data analysis.

2008/5. Giuseppe DE FEO. Efficiency gains and mergers.

2008/6. Gabriella MURATORE. Equilibria in markets with non-convexities and a solution to the missing money phenomenon in energy markets.

2008/7. Andreas EHRENMANN and Yves SMEERS. Energy only, capacity market and security of supply. A stochastic equilibrium analysis.

2008/8. Géraldine STRACK and Yves POCHET. An integrated model for warehouse and inventory planning.

2008/9. Yves SMEERS. Gas models and three difficult objectives.

2008/10. Pierre DEHEZ and Daniela TELLONE. Data games. Sharing public goods with exclusion.

2008/11. Pierre PESTIEAU and Uri POSSEN. Prodigality and myopia. Two rationales for social security.

2008/12. Tim COELLI, Mathieu LEFEBVRE and Pierre PESTIEAU. Social protection performance in the European Union: comparison and convergence.

2008/13. Loran CHOLLETE, Andréas HEINEN and Alfonso VALDESOGO. Modeling international financial returns with a multivariate regime switching copula.

2008/14. Filomena GARCIA and Cecilia VERGARI. Compatibility choice in vertically differentiated technologies.

2008/15. Juan D. MORENO-TERNERO. Interdependent preferences in the design of equal-opportunity policies.

\section{Books}

Y. POCHET and L. WOLSEY (eds.) (2006), Production planning by mixed integer programming. New York, Springer-Verlag.

P. PESTIEAU (ed.) (2006), The welfare state in the European Union: economic and social perspectives. Oxford, Oxford University Press.

H. TULKENS (ed.) (2006), Public goods, environmental externalities and fiscal competition. New York, Springer-Verlag.

V. GINSBURGH and D. THROSBY (eds.) (2006), Handbook of the economics of art and culture. Amsterdam, Elsevier.

J. GABSZEWICZ (ed.) (2006), La différenciation des produits. Paris, La découverte.

L. BAUWENS, W. POHLMEIER and D. VEREDAS (eds.) (2008), High frequency financial econometrics: recent developments. Heidelberg, Physica-Verlag.

P. VAN HENTENRYCKE and L. WOLSEY (eds.) (2007), Integration of AI and OR techniques in constraint programming for combinatorial optimization problems. Berlin, Springer.

\section{CORE Lecture Series}

C. GOURIÉROUX and A. MONFORT (1995), Simulation Based Econometric Methods.

A. RUBINSTEIN (1996), Lectures on Modeling Bounded Rationality.

J. RENEGAR (1999), A Mathematical View of Interior-Point Methods in Convex Optimization.

B.D. BERNHEIM and M.D. WHINSTON (1999), Anticompetitive Exclusion and Foreclosure Through Vertical Agreements.

D. BIENSTOCK (2001), Potential function methods for approximately solving linear programming problems: theory and practice.

R. AMIR (2002), Supermodularity and complementarity in economics.

R. WEISMANTEL (2006), Lectures on mixed nonlinear programming. 